\title{
Possible Correlation of b3-a2-type bcr-abl Messenger RNA Defined by Semiquantitative RT-PCR to Platelet and Megakaryocyte Counts in Philadelphia-positive Chronic Myelogenous Leukemia
}

\author{
Koiti InOKUChI, Makoto FutAKI, Kazuo DAN and Takeo Nomura
}

\begin{abstract}
Thirty-five patients with Philadelphia chromosome $\left(\mathbf{P h}^{\mathbf{1}}\right)$-positive chronic myelogenous leukemia (CML) were classified on the basis of the fusion pattern of bcr-abl mRNA determined by the reverse-transcriptase-polymerase chain reaction (RT-PCR) method. Semiquantitative assay of the bcr exon 2/abl exon 2 fused mRNA (b2-a2) and bcr exon 3/abl exon 2 fused mRNA (b3-a2) resulted in 21 patients showing b3-a2 type mRNA, seven showing b2-a2 type and seven showing coexpression. Quantification of the autoradiographic signals of amplified products was estimated using an MCID image analysis system. The relative intensity was defined as the ratio of $b c r-a b l$ signal to that of $B$-actin. The relationship between the semiquantified bcr-abl mRNA and the platelet/megakaryocyte counts was analyzed. A possible correlation was found between the semiquantified b3-a2 type $\mathrm{mRNA}$ and the platelet $(\mathrm{p}<.05, \mathrm{~N}=28)$ and megakaryocyte $(\mathrm{p}<.05, \mathrm{~N}=13)$ counts of these patients. This finding suggests the possibility that b3-a2 mRNA may affect the thrombopoietic activity in $\mathrm{Ph}^{1}$-positive $\mathrm{CML}$ in a dose-response manner.
\end{abstract}

(Internal Medicine 33: 189-192, 1994)

Key words: thrombopoiesis, CML, bcr-abl gene

\section{Introduction}

Philadelphia $\left(\mathrm{Ph}^{1}\right)$-positive chronic myelogenous leukemia (CML) is thought to be a clonal myeloproliferative disorder resulting from oncogenic transformation of a bone marrow stem cell. In the chronic phase, the disease phenotype is characterized by pronounced granulocytosis and thrombocytosis of peripheral blood and increased myeloid and megakaryocyte compartments in the hypercellular bone marrow. Some special phenotype is also characterized by marked thrombocytosis like essential thrombocythemia (ET) (1).

We recently reported a relationship between thrombopoiesis and the $b c r$-breakpoint zone (2). We also reported that the type of $b c r$ - $a b l$-mRNA was related only to the platelet count $(3,4)$. More recently, we found some CML patients with b3-a2 type mRNA have a rather high degree of thrombocytosis compared to the degree of leukocytosis, similar to in $\mathrm{Ph}^{1}$-positive ET (5, 6). Two $\mathrm{Ph}^{1}$-positive CML patients mimicking ET were also demonstrated to have a rearrangement within the 3' extreme site of M-BCR or b3-a2 type mRNA (7). Here, we attempted semiquantitative assay of the fused mRNA for 35 CML patients, and we studied the relationship between the semiquantified $b c r-a b l$ mRNA and the platelet/megakaryocyte counts. The present data of semiquantitative assay support an association between b3-a2 type of mRNA and increased thrombopoietic activity.

\section{Materials and Methods}

\section{Patients}

Bone marrow samples were obtained from $\mathrm{Ph}^{1}$-positive CML patients in the chronic phase of the disease. All (35) of the patients had not received therapy prior to RNA analysis. The clinical data of each patient are those obtained at the time of diagnosis of CML.

\section{Semiquantitative assay of bcr-abl $m R N A$}

We performed semiquantitative assay of the $b c r$-abl mRNA for the $26 \mathrm{CML}$ patients. The total RNA was isolated using isothiocyanate and supercentrifugation with $\mathrm{CsCl}$ from

From the Hematology Division of the Third Department of Internal Medicine, Nippon Medical School, Tokyo

Received for publication August 9, 1993; Accepted for publication December 27, 1993

Reprint requests should be addressed to Dr. Koiti Inokuchi, the Third Department of Internal Medicine, Nippon Medical School, 1-1-5, Sendagi, Bunkyo-ku, Tokyo 113 
mononuclear cells of bone marrow samples (8). Reverse transcription and polymerase chain reaction (RT-PCR) were performed using the methods described by Roth et al (9), with slight modification (4). 200-500 ng of RNA was reverse transcribed using oligonucleotide abl-RT as a primer. Then the synthesized cDNA was subjected to PCR analysis. PCR of 35 cycles was performed, consisting of 30 seconds at $94^{\circ} \mathrm{C}$ (denaturation), 30 seconds at $55^{\circ} \mathrm{C}$ (annealing), and 1 minute at $72^{\circ} \mathrm{C}$ (extension). The amplified products of the RT-PCR technique were analyzed by electrophoresis on $2 \%$ agarose gels and visualized by autoradiography. The amplified DNA was transferred onto a nylon filter and hybridized to ${ }^{32} \mathrm{P}$-labeled a bcrexon b2 probe ( $0.6 \mathrm{HB}$ probe; provided by Dr. S. Hirosawa, Tokyo Medical and Dental University). The primers used for this study were synthesized with an Applied Biosystems DNA synthesizer (California, USA).

The sequences of the oligomers were:

abl-RT (antisense strand): 5'-AACGAAAAGGTTGGGGTC3 '

bcr-1 (coding strand): 5'-AGCATGGCCTTCAGGGTGCACAGCCGCAACGGCAA-3'

abl-1 (antisense strand): 5'-TCACTGGGTCCAGCGAGAAGGTTTTCCTTGGAGTT-3'

Semiquantification of the autoradiographic signals was performed using an MCID image analysis system (Imaging Research, Inc.; St. Catherines Ontario, Canada). This system digitalizes a continuous range of gray image shades into 256 discrete gray levels, in which the lowest level is the darkest. The levels obtained were converted to relative optical densities (ROD) by the equation: ROD $=\log _{10}$ (256/level). The entire width of the autoradiogram lane was analyzed with appropriate background subtraction. All autoradiogram bands in one lane were analyzed together. The quality of the RNA and validity of the PCR amplifications were determined by amplification of Bactin sequences in the same specimens. The relative intensity was defined as the ratio of the $b c r$ - $a b l$ signal to that of $B$-actin. The $B$-actin sequences of the oligomers were:

actin-1 (antisense strand for cDNA synthesis and PCR): 5'TTCTCGCGGTTGGCCTTGGG-3'

actin-2 (coding strand for PCR): 5'-AACGGCTCCGGCATGTGCAA-3'.

actin-P (antisense strand for 5' end-labeled probe): 5'CTTCTGACCCATGCCCACCA-3'.

\section{Results}

\section{Expression type of bcr-abl chimeric $m R N A$}

The RNA samples from the $35 \mathrm{CML}$ patients were analyzed for specific $b c r-a b l$ mRNA junctions by the RT-PCR method. Two junctions, b2-a2 and b3-a2, were identified by their electrophoretic mobility and hybridization with a $b c r$ exon 2 probe. The 392-bp RT-PCR product is the band specific for b3a2 mRNA, while the 317-bp RT-PCR product is specific for b3a2 mRNA. The RT-PCR analysis of the patients showed the presence of b3-a2 mRNA in 21 cases and b2-a2 in seven cases, and coexpression of both junctions in seven cases.
Relationship between the type of bcr-abl mRNA and clinical parameters

The platelet counts of patients expressing b3-a2 mRNA were significantly higher than the count of patients expressing

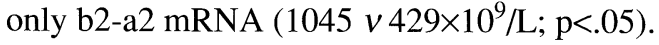

The relationship of the megakaryocyte count to the $b c r-a b l$ mRNA was also analyzed in some of the patients. There was a significant difference in the megakaryocyte count between the five patients with the $\mathrm{b} 2-\mathrm{a} 2$ type and the 13 patients with the $\mathrm{b} 3$ a2 type $\left(25.2 \vee 62.9 / \mathrm{mm}^{2} ; \mathrm{p}<.05\right)$. We found no significant correlation with any other clinical parameters (WBC count, hemoglobin).

\section{Relationship between the semiquantified bcr-ablmRNA and the} platelet and megakaryocyte counts

To assess the sensitivity of our semiquantitative assay of $b c r-a b l$ mRNA, we made serial dilutions of K562 RNA. For dilutions ranging from $10^{-5}$ to $10^{-2}$, we observed a linear increase in the intensity level of the $b c r-a b l$ signal and the $\beta$-actin signal (Fig. 1). When the K562 RNA was diluted 1-1,000 times, it was roughly equal to the density of $b c r-a b l$ of CML patients. This finding probably reflects the high expression of $b c r-a b l$ mRNA in K562 cells compared with its expression in the cells of CML patients. Figure 2 shows examples of Southern blot hybridization of RT-PCR products of the $b c r-a b l$ and $B$-actin mRNAs. Figure 3 shows a significant correlation between the increase in the relative intensity of the b3-a2 type $b c r-a b l$ mRNA and the increase in the platelet count $(\mathrm{p}<.05 ; \mathrm{N}=28)$. We also found a significant correlation between the relative intensity level with the b3-a2 type and the megakaryocyte counts $(\mathrm{p}<.05 ; \mathrm{N}=13)$ (Fig. 4). We could not demonstrate any correlation between the expression level and the platelet counts or

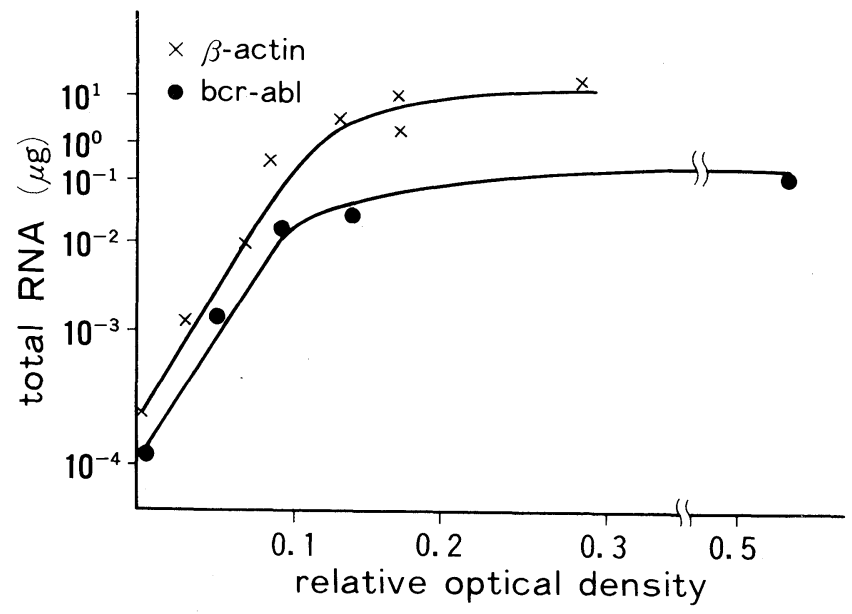

Fig. 1. Semiquantification of the hybrid $b c r-a b l$ mRNA and B-actin in serial dilutions from K562 mRNA. Semiquantification of the autoradiographic signals was performed using an MCID image analysis system. The levels obtained were converted to relative optical densities (ROD) by the equation: ROD $=\log _{10}$ (256/level). K562 mRNA showed the autoradiographic signals of the 392-bp RT-PCR product, which is the band specific for b3-a2 mRNA. The quality of RNA and the validity of the amplifications were determined by amplification of $B$-actin sequences in the same specimens. 


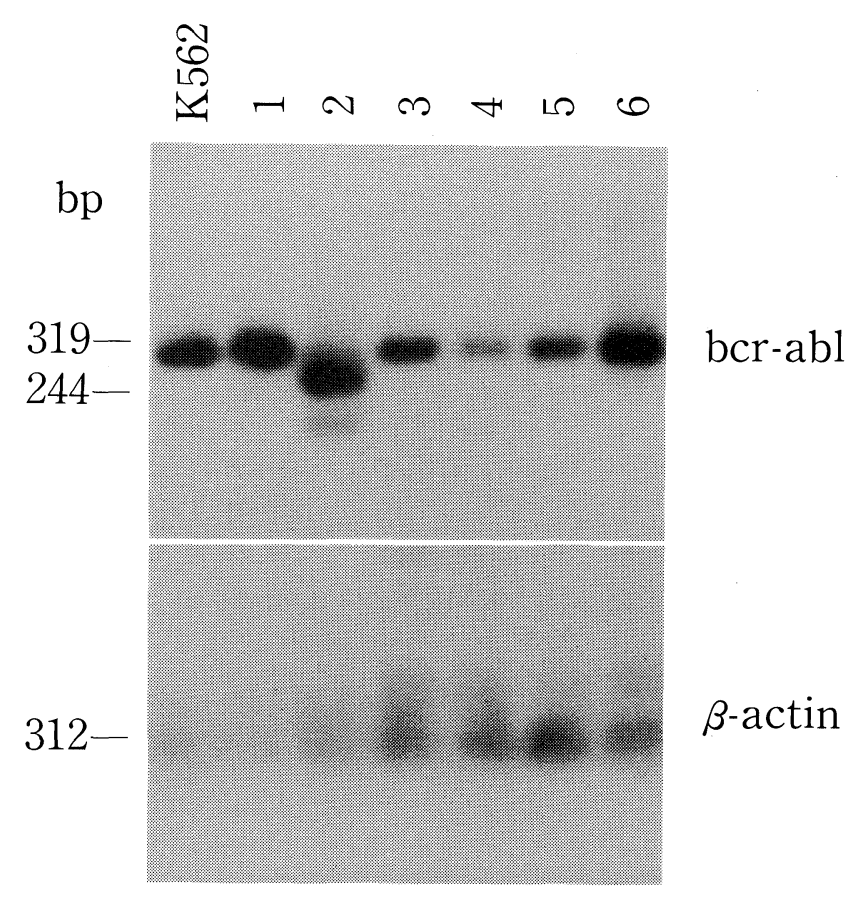

Fig. 2. Examples of Southern blot hybridization of semiquantitative RTPCR. Products from RT-PCR analyses were size-fractionated by $2.0 \%$ agarose gel electrophoresis, transferred to a nylon membrane, and hybridization to a bcr exon 2. The upper picture shows RT-PCR products of the $b c r-a b l$ mRNA. The lower picture shows that of the $\beta$-actin. The numbers identify individual patients' samples; K562-lane is shown as internal control. K562 cells and patients 1,3-6 have the $\mathrm{b} 3-\mathrm{a} 2$ junction, and patient 2 has the $\mathrm{b} 2-\mathrm{a} 2$ junction.

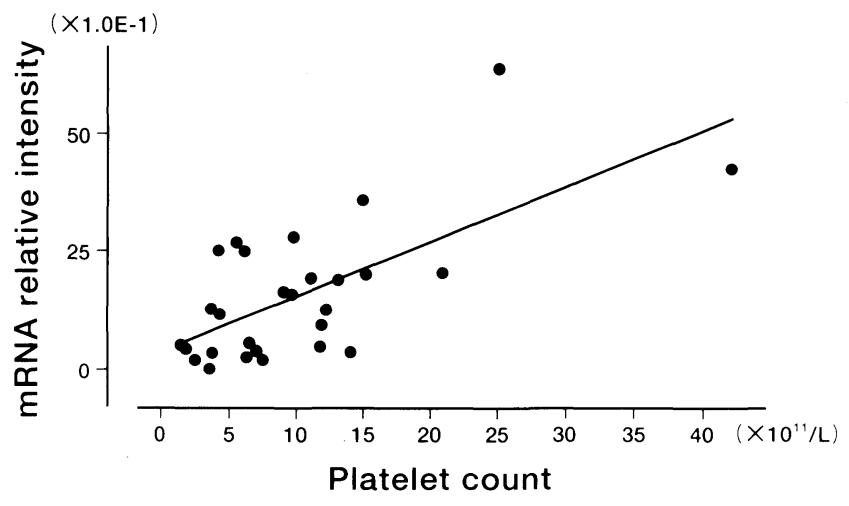

Fig. 3. Relationship between the platelet count and the $b c r$ - $a b l$ mRNA relative intensity level in 28 patients expressing b3-a2 mRNA. The mRNA relative intensity was calculated according to the method described in the text. A significant correlation $(\mathrm{p}<.05)$ was found between these two parameters. $\mathrm{Y}=0.269+0.119 \mathrm{X}, \mathrm{r}=0.673$.

megakaryocyte count in the group with b2-a2 mRNA.

\section{Discussion}

We recently found and reported that CML patients with 3'

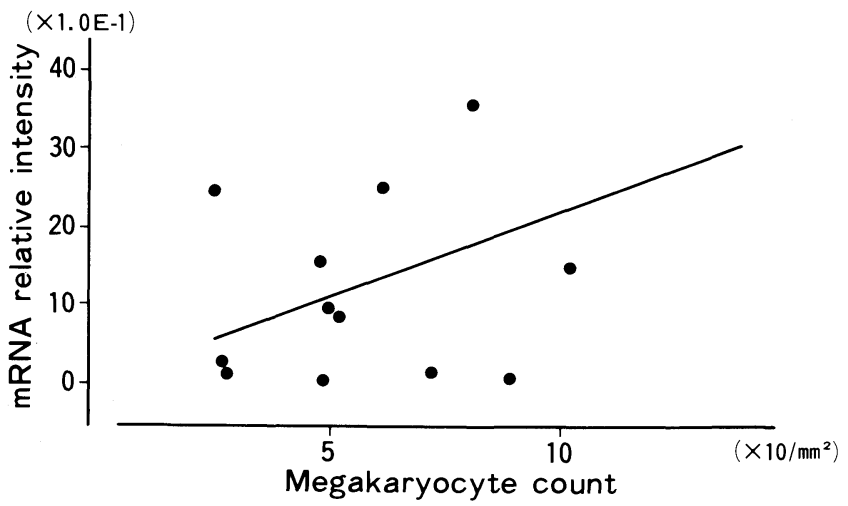

Fig. 4. Relationship between the megakaryocyte count and the $b c r-a b l$ mRNA relative intensity level in 13 patients expressing b3-a 2 mRNA. The mRNA relative intensity was calculated according to the method described in the text. Megakaryocytes were counted under a light microscope on histological sections prepared from bone marrow aspirates collected at diagnosis. A significant correlation $(\mathrm{p}<.05)$ was found between these two parameters. $\mathrm{Y}=0.364+0.021 \mathrm{X}, \mathrm{r}=0.659$.

breakpoint within the $b c r$ gene have higher thrombopoietic activity than those with a 5 ' breakpoint (2). We classified 57 patients on the basis of two different types of $b c r-a b l$ mRNA (b3-a2 and b2-a2) determined by the RT-PCR method, and showed that the platelet count at diagnosis is significantly higher in the b3-a2 group than in the b2-a2 group (3).

More recently, we found that some b3-a2 cases have a rather higher degree of thrombocytosis compared to the degree of leukocytosis, similar to $\mathrm{Ph}^{1}$-positive essential thrombocythemia (ET) $(5,6)$. This finding is consistent with the report of Martiat et al (10) that five of six cases of $\mathrm{Ph}^{1}$-positive ET, a disease thought to be a variant of CML, had the b3-a2 type mRNA. Two $\mathrm{Ph}^{1}$-positive CML patients mimicking ET were also demonstrated having a rearrangement within the 3 ' extreme site of MBCR or b3-a2 type mRNA (7). Thus, it is possible that thrombopoietic activity may predominate over granulopoiesis in some CML patients with high expression of the b3-a2 mRNA. We, therefore, speculate that the $\mathrm{P} 210 \mathrm{Bcr} / \mathrm{Abl}$ protein having the b3-exon sequence may have some thrombopoietic activity in itself. If true, the thrombopoietic activity would probably depend on the quantity of $b c r-a b l$ mRNA. Here, we attempted to analyze the relationship between semiquantified $b c r-a b l \mathrm{mRNA}$ and the platelet and megakaryocyte counts in a relatively small number of CML patients. A possible correlation of quantity of b3-a2-type mRNA to thrombopoiesis in $\mathrm{Ph}^{1}$ positive CML was found by semiquantitative RT-PCR.

In the patient group with $\mathrm{b} 3-\mathrm{a} 2 \mathrm{mRNA}$, there were many patients with a relatively low platelet count and high expression of b3-a2 mRNA as shown in Fig. 3. Thus, we should also explore whether other factors are involved in the increased thrombopoiesis in some cases of CML. The possibility that a 5' breakpoint in the $a b l$ gene may be associated with thrombocytosis should be investigated, as proposed by Morris et al (11). In this regard, it is note worthy that two patients who had pronounced 
thrombocytosis and a 5' breakpoint in the $a b l$ gene showed the b3-a2-type mRNA. Recently, abl-bcr mRNA has been noticed in CML patients (12). There is a possibility that this abl-bcr mRNA may also influence the clinical features of CML. There is also another possibility that the involvement of some cytokines may cause thrombocytosis in CML patients.

The present data of the semiquantitative assay support our previous data. We are now confident that the P210Bcr/Abl protein with b3 exon has thrombopoietic activity. Although the results are statistically significant, the $p$ value is low. Further studies with a large number of patients will help to clarify the thrombopoietic activity of this protein.

Acknowledgements: This work was supported in part by a Grant-in-Aid for General Scientific Research from the Ministry of Education, Science and Culture, by the Naito Foundation and by the Uehara Memorial Foundation. We thank Tokiko Inoue, Arinobu Tojo, Keiya Ozawa and Shigetaka Asano for supplying the blood samples used in this study. We are also indebted to Dr. S. Inokuchi for help in the preparation of this manuscript.

\section{References}

1) Masson JE, DeVita VT, Canellos GP. Thrombocytosis in chronic granulocytic leukemia: Incidence and clinical significance. Blood 44: 483, 1974.

2) Inokuchi $K$, Futaki $M$, Yamada $T$, et al. The relationship between the site of breakpoints within the bcr gene and thrombopoiesis of Philadelphiapositive chronic myelocytic leukemia. Leukem Res 15: 1067, 1991.
3) Inokuchi $\mathrm{K}$, Inoue $\mathrm{T}$, Tojo A, et al. A possible correlation between the type of bcr-abl hybrid messenger RNA and platelet count in Philadelphiapositive chronic myelogenous leukemia. Blood 78: 3125, 1991.

4) Futaki M, Inokuchi K, Matsuoka H, Miyake K, Dan K, Nomura T. Relationship of the type of bcr-abl hybrid mRNA to clinical course and transforming activity in Philadelphia-positive chronic myelogenous leukemia. Leukem Res 16: 1071, 1992.

5) Inokuchi K, Nomura $T$. The relationship between the type of bcr-abl hybrid messenger RNA and thrombopoiesis in Philadelphia-positive chronic myelogenous leukemia. Leukem Lymphom 10: 9, 1993.

6) Inokuchi K, Futaki M, Miyake M, et al. Molecular breakpoints and platelet counts in chronic myeloid leukemia; response. Blood 80: 556, 1992.

7) Cervantes F, Urbano-Ispizua A, Villamor N, et al. Ph-positive chronic myeloid leukemia mimicking essential thrombocythemia and terminating into megakaryoblastic blast crisis: report of two cases with molecular studies. Leukemia 7: 327, 1993.

8) Chirgwin JM, Przybyla AE, MacDonald RJ, Rutter WJ. Isolation of biologically active ribonucleic acid from sources enriched in ribonuclease. Biochemistry 18: 5294, 1979.

9) Roth MS, Antin JH, Bingham EL, Ginsburg D. Detection of Philadelphiapositive cells by polymerase chain reaction following bone marrow transplant for chronic myelogenous leukemia. Blood 74: 882, 1989.

10) Martiat P, Ifrah N, Rassool F, et al. Molecular analysis of Philadelphiapositive essential thrombocythemia. Leukemia 3: 563, 1989.

11) Morris CM, Heisterkamp N, Groffen J. Entire abl gene is joined with 5'BCR in some patients with Philadelphia-positive leukemia. Blood 78: 1078, 1991.

12) Melo JV, Gordon DE, Cross NCP, Goldman JM. The abl-bcr fusion gene is chronic myeloid leukemia. Blood 81: 158, 1993. 